\title{
Asymptotic Boundary-Layer Solutions for Mixed Convection from a Vertical Surface in a Micropolar Fluid
}

\author{
Rama Subba Reddy Gorla \\ Cleveland State University, r.gorla@csuohio.edu \\ Paul P. Lin \\ Cleveland State University, p.lin@csuohio.edu
}

An-Jen J. Yang

Cleveland State University

Follow this and additional works at: https://engagedscholarship.csuohio.edu/enme_facpub

Part of the Complex Fluids Commons, and the Transport Phenomena Commons

How does access to this work benefit you? Let us know!

\section{Publisher's Statement}

NOTICE: this is the author's version of a work that was accepted for publication in International Journal of Engineering Science. Changes resulting from the publishing process, such as peer review, editing, corrections, structural formatting, and other quality control mechanisms may not be reflected in this document. Changes may have been made to this work since it was submitted for publication. A definitive version was subsequently published in International Journal of Engineering Science, 28, 6, (01-01-1990); 10.1016/0020-7225(90)90054-M

\section{Original Citation}

Gorla, R., Lin, P., , \& An-Jen, Y. (1990). Asymptotic boundary layer solutions for mixed convection from a vertical surface in a micropolar fluid. International Journal of Engineering Science, 28(6), 525-533.

doi:10.1016/0020-7225(90)90054-M

This Article is brought to you for free and open access by the Mechanical Engineering Department at EngagedScholarship@CSU. It has been accepted for inclusion in Mechanical Engineering Faculty Publications by an authorized administrator of EngagedScholarship@CSU. For more information, please contact library.es@csuohio.edu. 


\title{
ASYMPTOTIC BOUNDARY LAYER SOLUTIONS FOR MIXED CONVECTION FROM A VERTICAL SURFACE IN A MICROPOLAR FLUID
}

\author{
RAMA SUBBA REDDY GORLA, PAUL P. LIN and AN-JEN YANG \\ Department of Mechanical Engineering, Cleveland State University, Cleveland, $\mathrm{OH} 44115$, U.S.A.
}

\begin{abstract}
Using the theory of micropolar fluids due to Eringen, asymptotic boundary layer solutions are presented to study the combined convection from a vertical semi-infinite plate to a micropolar fluid. Consideration is given to the region close to the leading edge as well as the region far away from the leading edge. Numerical results are obtained for the velocity, angular velocity and temperature distribution. The missing wall values of the velocity, angular velocity and thermal functions are tabulated. Micropolar fluids display drag reduction and reduced surface heat transfer rate when compared to Newtonian fluids.
\end{abstract}

\section{INTRODUCTION}

Mixed convection from a semi-infinite vertical surface in Newtonian fluids has been analyzed by many investigators [1-3]. The two important circumstances that arise are due to the buoyancy forces aiding or opposing the forced flow. In the case of buoyancy-opposed regime, an adverse pressure gradient is caused by the buoyancy force. As a result, the external flow separates and reverses direction at some location downstream. Since similarity solutions are not possible for this and for many mixed convection flows, perturbation and finite difference methods are often used.

Although the previously mentioned investigations have been carried out for the Newtonian fluids, there exist relatively fewer studies concerning non-Newtonian fluids with microstructures such as polymeric additives, colloidal suspensions, animal blood, liquid crystals, fluid with additives etc. Eringen [4] has developed the theory of micropolar fluids which show microrotatation effects as well as micro-inertia. The theory of thermomicropolar fluids was developed by Eringen [5] by extending the theory of micropolar fluids. Gorla [6] studied the thermal boundary layer of a micropolar fluid at a stagnation point using the theory of micropolar fluids due to Eringen. The forced convective heat transfer characteristics of the micropolar fluid flow over a flat plate have been investigated by Gorla [7]. Jena and Mathur [8] obtained a similarity solution for the laminar free convective flow of a thermomicropolar fluid along a vertical flat plate.

In this paper, we have considered the mixed convection in the micropolar boundary layer flow on a vertical flat plate maintained at a uniform temperature $T_{w}$. A uniform laminar, incompressible, steady, micropolar fluid stream at velocity $U_{\infty}$ and temperature $T_{\infty}$ flows parallel to the surface. A Blausius flow dominates near the leading edge where the buoyancy effects appear only as a perturbation of the imposed flow $U_{\infty}$. Far downstream of the leading edge, for aiding effects, the flow is dominated by the buoyancy forces and the forced flow effect appears as a perturbation. Asymptotic boundary layer solutions are derived for the two regions, near as well as far away from the leading edge. Numerical results are presented for a range of values of the dimensionless material properties and Prandtl number of the fluid.

\section{ANALYSIS}

The governing equations for a steady, laminar, incompressible, micropolar fluid over a semi-infinite vertical flat plate with variable micro-inertia may be written within boundary layer approximation as:

$$
\frac{\partial u}{\partial x}+\frac{\partial v}{\partial y}=0
$$




$$
\begin{gathered}
\rho\left(u \frac{\partial u}{\partial x}+v \frac{\partial u}{\partial y}\right)=(\mu+\kappa) \frac{\partial^{2} u}{\partial y^{2}}+\kappa \frac{\partial N}{\partial y}+\rho g \beta\left(t-T_{\infty}\right) \\
\rho j\left(u \frac{\partial N}{\partial x}+v \frac{\partial N}{\partial y}\right)=-\kappa\left(2 N+\frac{\partial u}{\partial y}\right)+\gamma \frac{\partial^{2} N}{\partial y^{2}} \\
\rho C p\left[u \frac{\partial T}{\partial x}+v \frac{\partial T}{\partial y}\right]=\kappa_{f} \frac{\partial^{2} T}{\partial y^{2}}
\end{gathered}
$$

The boundary condition for the velocity field may be written as

$$
\begin{array}{cl}
y=0: & u=v=0, \quad N=0 \\
y \rightarrow \infty: & u \rightarrow U_{\infty}, \quad N \rightarrow 0
\end{array}
$$

For the temperature field, we have

$$
\begin{array}{cc}
y=0: & T=T_{w} \\
y \rightarrow \infty: & T \rightarrow T_{\infty}
\end{array}
$$

Proceeding with the analysis, we define a stream function $\psi$ such that

and

$$
u=\frac{\partial \psi}{\partial y}
$$

$$
v=-\frac{\partial \psi}{\partial x}
$$

\section{Near the leading edge solution}

In this region, forced flow dominates since the buoyancy force has acted over a small vertical distance. We now define the following dimensionless variables:

$$
\begin{gathered}
\eta=\left(\frac{U_{\infty}}{2 v x}\right)^{1 / 2} y \\
\xi=\frac{g \beta\left(T_{w}-T_{\infty}\right) x}{U_{\infty}^{2}}=\frac{\mathrm{Gr}_{x}}{\mathrm{Re}_{x}^{2}} \\
\psi=\left(2 v U_{\infty} x\right)^{1 / 2} f(\xi, \eta) \\
N=\left(\frac{U_{\infty}}{2 v x}\right)^{1 / 2} \cdot U_{\infty} \cdot g(\xi, \eta) \\
\theta=\frac{T-T_{\infty}}{T_{w}-T_{\infty}}
\end{gathered}
$$

After substituting expressions in equation (7) into equations (2)-(4), we have:

$$
\begin{gathered}
(1+\Delta) f^{\prime \prime \prime}+f f^{\prime \prime}+\Delta g^{\prime} \pm 2 \xi \theta=2 \xi\left[f^{\prime} \frac{\partial f}{\partial \xi}-f^{\prime \prime} \frac{\partial f}{\partial \xi}\right] \\
\lambda G g^{\prime \prime}-2 \lambda\left(2 g+f^{\prime \prime}\right)+G\left(f^{\prime} g+f g^{\prime}\right)=2 g \xi\left[g^{\prime} \frac{\partial f}{\partial \xi}-f^{\prime} \frac{\partial g}{\partial \xi}\right] \\
\frac{\theta^{\prime \prime}}{\operatorname{Pr}}+f \theta^{\prime}=2 \xi\left[f^{\prime} \frac{\partial \theta}{\partial \xi}-\theta^{\prime} \frac{\partial f}{\partial \xi}\right]
\end{gathered}
$$

In the above equations, a prime denotes differentiation with respect to $\eta$ only. The transformed boundary conditions are given by:

$$
\begin{gathered}
f(\xi, 0)=f^{\prime}(\xi, 0)=0, \quad f^{\prime}(\xi, \infty)=1 \\
g(\xi, 0)=g(\xi, \infty)=0 \\
\theta(\xi, 0)=1, \quad \theta(\xi, \infty)=0
\end{gathered}
$$


In order to solve the governing conservation equations, we assume that

$$
\begin{aligned}
& f(\xi, \eta)=f_{0}(\eta)+\xi \cdot f_{1}(\eta)+\xi^{2} \cdot f_{2}(\eta)+\cdots \\
& g(\xi, \eta)=g_{0}(\eta)+\xi \cdot g_{1}(\eta)+\xi^{2} \cdot g_{2}(\eta)+\cdots \\
& \theta(\xi, \eta)=\theta_{0}(\eta)+\xi \cdot \theta_{1}(\eta)+\xi^{2} \cdot \theta_{2}(\eta)+\cdots
\end{aligned}
$$

When the expressions in equation (12) are substituted into equations (8), (9) and (10) and terms involving equal powers of $\xi$ and equated to zero, one obtains a set of ordinary differential equations governing the momentum, angular momentum and energy fields. These details are not shown here in order to conserve space. Equations governing $f_{i}(\eta), g_{i}(\eta)$ and $\theta_{i}(\eta)$ have been solved on an IBM 370 computer using the fourth order Runge-Kutta method of numerical integration procedure. The double precision arithmetic was used in all the computations. A step size of $\Delta \eta=0.001$ was selected. The missing wall values $f_{i}^{\prime \prime}(0), g_{i}^{\prime}(0)$ and $\theta_{i}^{\prime}(0)$ were determined by shooting techniques.

The shear stress at the surface of the plate is given by:

$$
\tau_{w}=\mu U_{x}\left(\frac{\rho U_{\infty}}{2 \mu x}\right)^{1 / 2} \cdot(1+\Delta) \cdot f^{\prime \prime}(\xi, 0)
$$

The friction coefficient is given by

$$
C_{f}=\frac{\tau_{w}}{\left(\rho U_{\infty}^{2} / 2\right)}=(1+\Delta) \cdot \sqrt{2} \cdot f^{\prime \prime}(\xi, 0) \cdot \mathrm{Re}_{x}^{-1 / 2}
$$

where $\operatorname{Re}_{x}=\left(\rho U_{\infty} x / \mu\right)$. The local heat flux may be written by Fourier's law as

$$
q_{w}(x)=-\kappa_{f} \cdot \frac{\partial T}{\partial y}=-\kappa_{f} \cdot\left(T_{w}-T_{\infty}\right)\left(\frac{\rho U_{\infty}}{2 \mu x}\right)^{1 / 2} \cdot \theta^{\prime}(\xi, 0)
$$

The local heat transfer coefficient is given by

$$
h(x)=\frac{q_{w}(x)}{\left(T_{w}-T_{\infty}\right)}
$$

The local Nusselt number can be written as

$$
\mathrm{Nu}_{x}=\frac{h x}{\kappa_{f}}=-\frac{1}{\sqrt{2}} \cdot \operatorname{Re}_{x}^{1 / 2} \cdot \theta^{\prime}(\xi, 0)
$$

Figures 1-3 display the numerical results obtained for the distribution of functions representing velocity, angular velocity and temperature within the boundary layer. The values

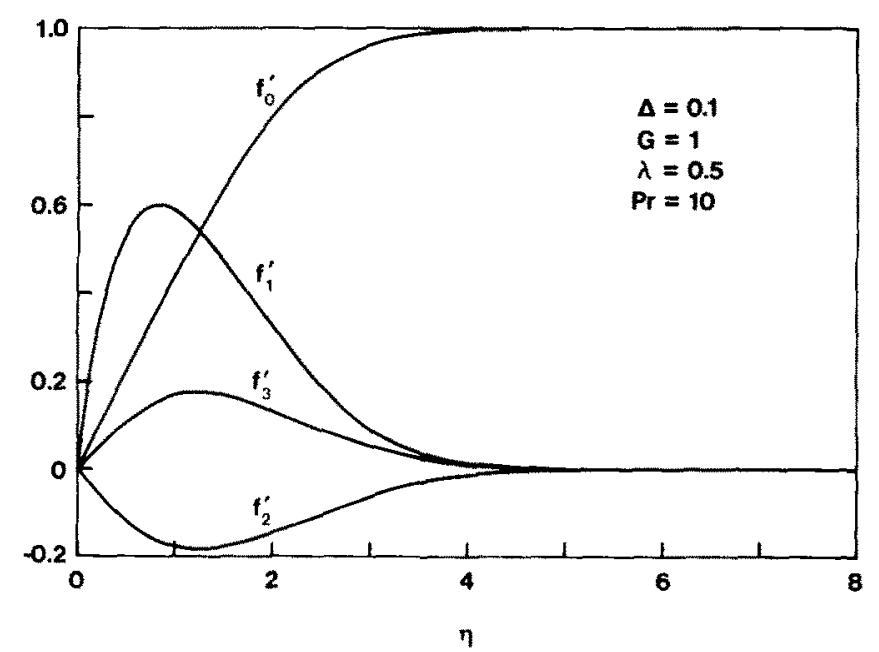

Fig. 1. Distribution of velocity functions (near the leading edge region). 


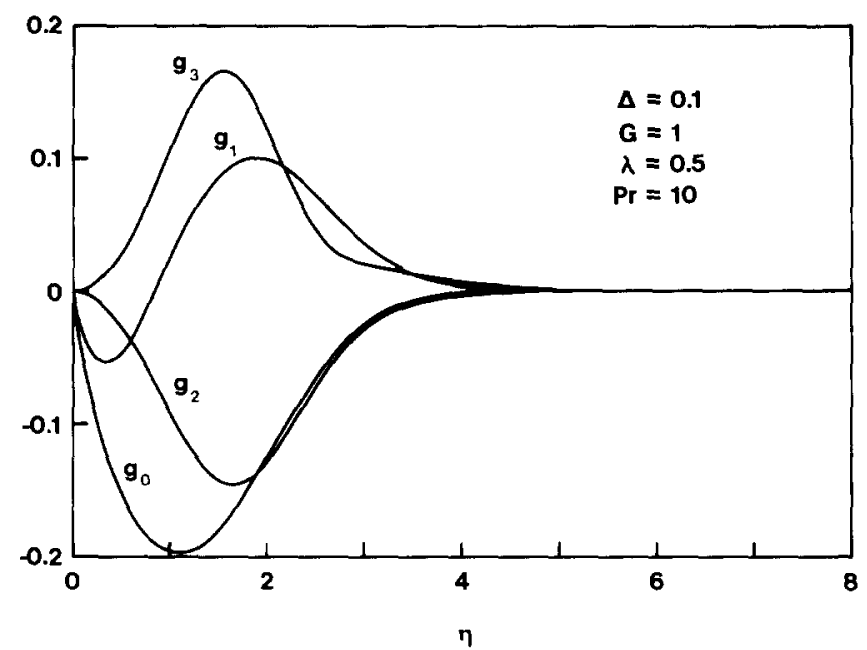

Fig. 2. Distribution of angular velocity functions (near the leading edge region).

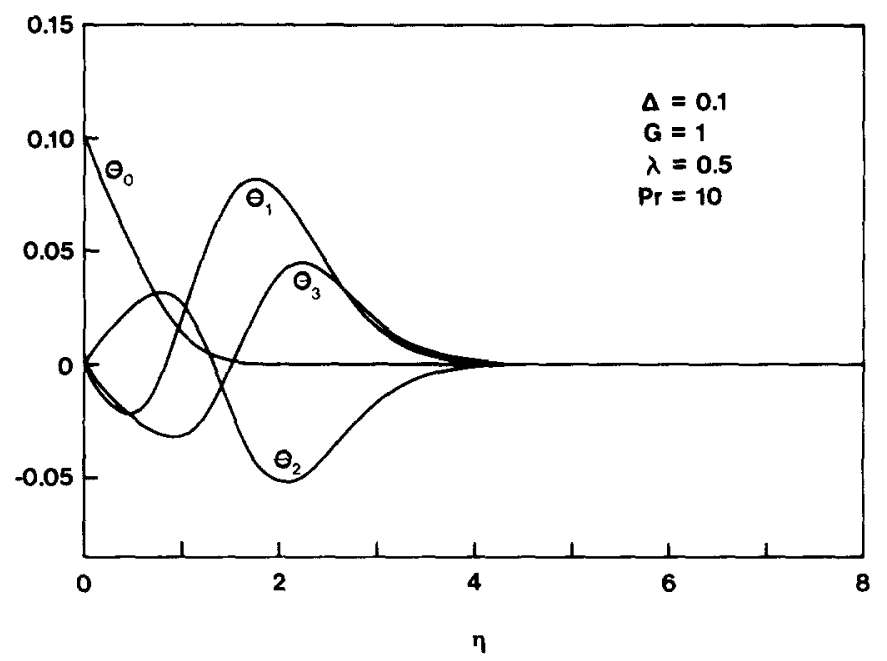

Fig. 3. Distribution of temperature functions (near the leading edge region).

Table 1. Values of $f_{0}^{\prime \prime}(0), f_{1}^{\prime \prime}(0), f_{2}^{\prime \prime}(0)$ and $f_{3}^{\prime \prime}(0)$ (near the leading edge solution)

\begin{tabular}{ccccccc}
\hline$\Delta$ & $G$ & $\lambda$ & $f_{\mathrm{n}}^{\prime \prime}(0)$ & $f_{1}^{\prime \prime}(0)$ & $f_{2}^{\prime \prime}(0)$ & $f_{3}^{\prime \prime}(0)$ \\
\hline 0.00 & 1. & 0.5 & 0.469250 & 0.974180 & -0.130830 & 0.112333 \\
0.00 & 2. & 0.5 & 0.469530 & 0.975056 & -0.140198 & 0.122020 \\
0.00 & 1. & 5.0 & 0.469540 & 0.975046 & -0.140951 & 0.119485 \\
0.00 & 2. & 5.0 & 0.469540 & 0.975046 & -0.154389 & 0.133200 \\
0.10 & 1. & 0.5 & 0.438820 & 0.908811 & -0.124322 & 0.110093 \\
0.10 & 2. & 0.5 & 0.439990 & 0.898568 & -0.184024 & 0.176984 \\
0.10 & 1. & 5.0 & 0.440000 & 0.907281 & -0.124868 & 0.103236 \\
0.10 & 2. & 5.0 & 0.440000 & 0.909303 & -0.138013 & 0.116560 \\
0.15 & 1. & 0.5 & 0.425000 & 0.879736 & -0.108626 & 0.089230 \\
0.15 & 2. & 0.5 & 0.426650 & 0.859106 & -0.100808 & 0.079257 \\
0.15 & 1. & 5.0 & 0.426088 & 0.877778 & -0.118327 & 0.096894 \\
0.15 & 2. & 5.0 & 0.427028 & 0.880046 & -0.130874 & 0.109387 \\
\hline
\end{tabular}


Table 2. Values of $g_{0}^{\prime \prime}(0), g_{1}^{\prime \prime}(0), g_{2}^{\prime \prime}(0)$ and $g_{3}^{\prime \prime}(0)$ (near the leading edge solution)

\begin{tabular}{ccccccc}
\hline$\Delta$ & $G$ & $\lambda$ & $g_{0}^{\prime}(0)$ & $g_{1}^{\prime}(0)$ & $g_{2}(0)$ & $g_{3}^{\prime}(0)$ \\
\hline 0.00 & 1. & 0.5 & -0.482950 & -0.403250 & 0.00 & 0.00 \\
0.00 & 2. & 0.5 & -0.347348 & -0.603250 & 0.00 & 0.00 \\
0.00 & 1. & 5.0 & -0.453295 & -0.397105 & 0.102971 & -0.090995 \\
0.00 & 2. & 5.0 & -0.307613 & -0.207842 & 0.066252 & -0.060152 \\
0.10 & 1. & 0.5 & -0.463894 & -0.389483 & 0.00 & 0.00 \\
0.10 & 2. & 0.5 & -0.383425 & -0.384325 & 0.00 & 0.00 \\
0.10 & 1. & 5.0 & -0.435376 & -0.379945 & 0.09346 & -0.080537 \\
0.10 & 2. & 5.0 & -0.295924 & -0.200578 & 0.061013 & -0.054186 \\
0.15 & 1. & 0.5 & -0.454758 & -0.382245 & 0.093466 & -0.080537 \\
0.15 & 2. & 0.5 & -0.329922 & -0.382245 & 0.093466 & -0.080537 \\
0.15 & 1. & 5.0 & -0.426355 & -0.372491 & 0.089584 & -0.076455 \\
0.15 & 2. & 5.0 & -0.290637 & -0.197197 & 0.058640 & -0.051518 \\
\hline
\end{tabular}

Table 3. Values of $\theta_{0}^{\prime}(0), \theta_{1}^{\prime}(0), \theta_{2}^{\prime}(0)$ and $\theta_{3}^{\prime}(0)$ (near the leading edge solution)

\begin{tabular}{ccccccc}
\hline$\Delta$ & $G$ & $\lambda$ & $\theta_{0}^{\prime}(0)$ & $\theta_{1}^{\prime}(0)$ & $\theta_{2}^{\prime}(0)$ & $\theta_{3}^{\prime}(0)$ \\
\hline 0.00 & 1. & 0.5 & -1.024740 & -0.070756 & 0.005053 & -0.055079 \\
0.00 & 2. & 0.5 & -1.024365 & -0.070894 & 0.054542 & -0.055247 \\
0.00 & 1. & 5.0 & -1.024375 & -0.063622 & 0.047328 & -0.048119 \\
0.00 & 2. & 5.0 & -1.024375 & -0.063057 & 0.044775 & -0.045969 \\
0.10 & 1. & 0.5 & -1.007875 & -0.069413 & 0.053271 & -0.053723 \\
0.10 & 2. & 0.5 & -1.007675 & -0.128509 & 0.084433 & -0.093211 \\
0.10 & 1. & 5.0 & -1.008250 & -0.061911 & 0.044327 & -0.043702 \\
0.10 & 2. & 5.0 & -1.006875 & -0.061425 & 0.042253 & -0.042257 \\
0.15 & 1. & 0.5 & -1.000000 & -0.068714 & 0.050676 & -0.048300 \\
0.15 & 2. & 0.5 & -0.999688 & -0.066956 & 0.046181 & -0.041736 \\
0.15 & 1. & 5.0 & -1.000125 & -0.061065 & 0.043063 & -0.041952 \\
0.15 & 2. & 5.0 & -0.998844 & -0.060634 & 0.041077 & -0.040564 \\
\hline
\end{tabular}

of $f_{0}^{\prime \prime}(0), f_{1}^{\prime \prime}(0), f_{2}^{\prime \prime}(0)$ and $f_{3}^{\prime \prime}(0)$ which are proportional to the friction factor have been tabulated in Table 1. Table 2 displays values of $g_{i}^{\prime}(0)$ for $i=0,1,2$ and 3 which should be useful in the calculation of wall couple stress. The values of $\theta_{0}^{\prime}(0), \theta_{1}^{\prime}(0), \theta_{2}^{\prime}(0)$ and $\theta_{3}^{\prime}(0)$ which are proportional to the Nusselt number have been tabulated in Table 3. As $\Delta$ increases, it may be observed that both the friction factor and the Nusselt number decrease. The results clearly demonstrated that the micropolar fluids display drag reduction as well as heat transfer rate reduction, when compared to Newtonian fluids $(\Delta=0)$. As the buoyancy parameter $\xi$ increases, the heat transfer rate is augmented.

\section{Far from the leading edge solution}

Far downstream from the leading edge, buoyancy forces dominate the flow. For this case, we define

$$
\begin{gathered}
\eta=\left(\frac{\mathrm{Gr}_{x}}{4}\right)^{1 / 4} \cdot \frac{y}{x} \\
\xi=\frac{\mathrm{Gr}_{x}}{\operatorname{Re}_{x}^{2}}=\frac{g \beta\left(T_{w}-T_{\infty}\right) x}{U_{\infty}^{2}} \\
\psi=4 v\left(\frac{\mathrm{Gr}_{x}}{4}\right)^{1 / 4}\left[F_{0}(\eta)+\xi^{-1 / 2} F_{1}(\eta)+\xi^{-1} \log \xi \bar{F}_{2}(\eta)+\xi^{-1} F_{2}(\eta)+\cdots\right] \\
N=\frac{4 U_{\infty}^{2}}{v} \cdot \xi\left[S_{0}(\eta)+\xi^{-1 / 2} S_{1}(\eta)+\xi^{-1} \log \xi \bar{S}_{2}(\eta)+\xi^{-1} S_{2}(\eta)+\cdots\right] \\
\theta=\frac{T-T_{\infty}}{T_{w}-T_{\infty}}=\left[H_{0}(\eta)+\xi^{-1 / 2} H_{1}(\eta)+\xi^{-1} \log \xi \bar{H}_{2}(\eta)+\xi^{-1} H_{2}(\eta)+\cdots\right] \\
\operatorname{Gr}_{x}=\frac{x^{3} g \beta\left(T_{w}-T_{\infty}\right)}{v^{2}} \\
\operatorname{Re}_{x}=\frac{U_{\infty} x}{v}
\end{gathered}
$$


The overbars indicate variables which are associated with the above transformation are to be applied for downstream where the buoyancy effects are dominant.

After substituting expressions in (18) into equations (2)-(4) we obtain the following ordinary differential equations:

$$
\begin{gathered}
(1+\Delta) F_{0}^{\prime \prime \prime}-2\left(F_{0}^{\prime}\right)^{2}+3 F_{0} F_{0}^{\prime \prime}+\Delta S_{0}^{\prime}+H_{0}=0 \\
(1+\Delta) F_{1}^{\prime \prime}+3 F_{0} F_{1}^{\prime \prime}-2 F_{0}^{\prime} F_{1}^{\prime}+F_{1} F_{0}^{\prime \prime}+\Delta S_{1}^{\prime}+H_{1}=0 \\
(1+\Delta) \bar{F}_{2}^{\prime \prime \prime}+3 F_{0} \bar{F}_{2}^{\prime \prime}-F_{0}^{\prime \prime} \bar{F}_{2}+\Delta S_{2}^{\prime}+\bar{H}_{2}=0 \\
(1+\Delta) F_{2}^{\prime \prime}+3 F_{0} F_{2}^{\prime \prime}-F_{0}^{\prime \prime} F_{2}+F_{1} F_{1}^{\prime \prime}+\Delta S_{2}^{\prime}+H_{2}=0 \\
\lambda S_{0}^{\prime \prime}-\left(\Delta \lambda_{1}+4 F_{0}^{\prime}\right) S_{0}-\Delta \lambda_{2} F_{1}^{\prime \prime}+3 F_{0} S_{0}^{\prime}=0 \\
\lambda S_{1}^{\prime \prime}-\left(\Delta \lambda_{1}+2 F_{0}^{\prime}\right) S_{1}-4 F_{1}^{\prime} S_{0}^{\prime}-\Delta \lambda_{2} F_{1}^{\prime \prime}+3 F_{0} S_{1}^{\prime}+F_{1} S_{0}^{\prime}=0 \\
\lambda \bar{S}_{2}^{\prime \prime}-\Delta \lambda_{1} \bar{S}_{2}-4 \bar{F}_{2}^{\prime} S_{0}-\Delta \lambda_{2} \bar{F}_{2}^{\prime \prime}+3 F_{0} \bar{S}_{2}^{\prime}-\bar{F}_{2} S_{0}^{\prime}=0 \\
\lambda S_{2}^{\prime \prime}-\Delta \lambda_{1} S_{2}-4 F_{2}^{\prime} S_{0}-\Delta \lambda_{2} F_{2}^{\prime \prime}+3 F_{0} S_{2}^{\prime}-F_{2} S_{0}^{\prime}=0 \\
H_{0}^{\prime \prime}+3 \operatorname{Pr} F_{0} H_{0}^{\prime}=0 \\
H_{1}^{\prime \prime}+\operatorname{Pr}\left(2 F_{0}^{\prime} H_{1}+3 F_{0} H_{1}+F_{1} H_{0}^{\prime}\right)=0 \\
\bar{H}_{2}^{\prime \prime}+\operatorname{Pr}\left(3 F_{0} \bar{H}_{2}^{\prime}-\bar{F}_{2} H_{0}^{\prime}+4 F_{0}^{\prime} \bar{H}_{2}\right)=0 \\
H_{2}^{\prime \prime}+\operatorname{Pr}\left(F_{1} H_{1}^{\prime}+2 F_{1}^{\prime} H_{1}-F_{2} H_{0}^{\prime}+3 F_{1} H_{2}^{\prime}+4 F_{0}^{\prime} H_{2}\right)=0
\end{gathered}
$$

The appropriate boundary conditions are given by

$$
\begin{gathered}
F_{0}(0)=F_{1}(0)=\bar{F}_{2}(0)=F_{2}(0)=0 \\
F_{0}^{\prime}(0)=F_{1}^{\prime}(0)=\bar{F}_{2}^{\prime}(0)=F_{2}^{\prime}(0)=0 \\
S_{0}(0)=S_{1}(0)=\bar{S}_{2}(0)=S_{2}(0)=0 \\
H_{0}(0)=1, \quad H_{1}(0)=\bar{H}_{2}(0)=H_{2}(0)=0 \\
F_{0}^{\prime}(\infty)=0, \quad F_{1}^{\prime}(\infty)=1 / 2, \quad \bar{F}_{2}^{\prime}(\infty)=F_{2}^{\prime}(\infty)=0 \\
S_{0}(\infty)=S_{1}(\infty)=\bar{S}_{2}(\infty)=S_{2}(\infty)=0 \\
H_{0}(\infty)=H_{1}(\infty)=\bar{H}_{2}(\infty)=H_{2}(\infty)=0
\end{gathered}
$$

The local shear stress and heat transfer at the surface are obtained as:

$$
\begin{gathered}
\tau_{w}=\frac{4 \mu(1+\Delta) v}{x^{2}}\left(\frac{\mathrm{Gr}_{x}}{4}\right)^{3 / 4}\left[F_{0}^{\prime \prime}(0)+\xi^{-1 / 2} F_{1}^{\prime \prime}(0)+\xi^{-1} \log \xi \bar{F}_{2}^{\prime \prime}(0)+\xi^{-1} F_{2}^{\prime \prime}(0)+\cdots\right] \\
\mathrm{Nu}_{x}=\frac{h_{x}}{k_{f}}=-\left(\frac{\mathrm{Gr}_{x}}{4}\right)^{1 / 4}\left[H_{0}^{\prime}(0)+\xi^{-1 / 2} H_{1}^{\prime}(0)+\xi^{-1} \log \xi \bar{H}_{2}^{\prime}(0)+\xi^{-1} H_{2}^{\prime}(0)+\cdots\right]
\end{gathered}
$$

Figures 4-6 show the results for the velocity, angular velocity and temperature functions for this region. Tables 4-6 display the missing wall functions for the velocity, angular velocity and temperature functions. These quantities are useful in the evaluation of wall shear stress, wall couple stress and the surface heat transfer rate. The results indicate that the friction factor and heat transfer rate decrease as $\Delta$ increases. Micropolar fluids display reduction in drag as well as heat transfer rate when compared to Newtonian fluids. As the buoyancy parameter increases, heat transfer rate gets augmented.

In order to provide a matching between the two asymptotic solutions, one valid for the leading edge proximity and the other valid for far away distances from the leading edge region, we have proposed a graphical method. Figure 7 displays the friction factor vs $\xi$ in which the two asymptotic solutions from equations (14) and (32) are plotted. Results for the intermediate values of $\xi$ are obtained by the proposed matching of the two solutions by a smooth solid curve. Figure 8 shows the results for the Nusselt number versus $\xi$. Solutions for small $\xi$ and large $\xi$ are obtained from equations (17) and (33), respectively. The solid curve denotes the matching between these two solutions. 


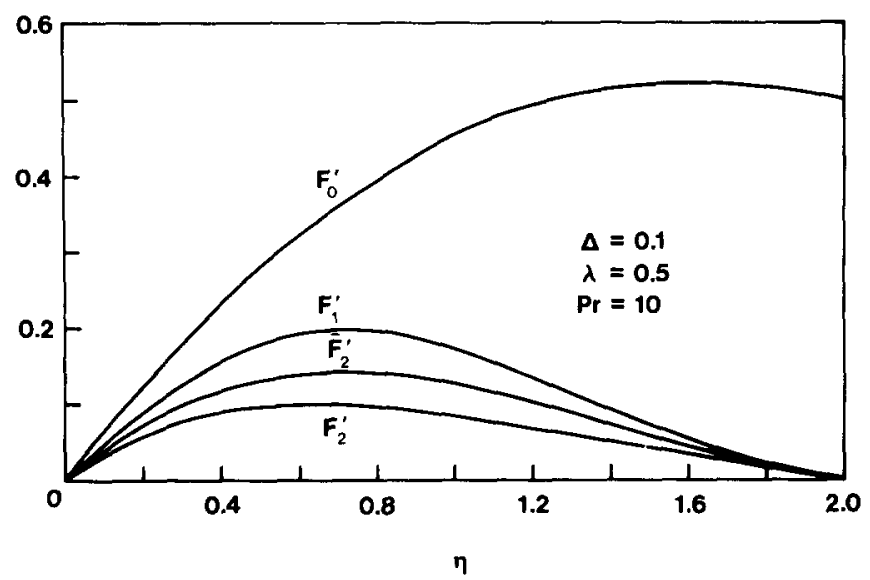

Fig. 4. Distribution of velocity functions (far away from the leading edge).

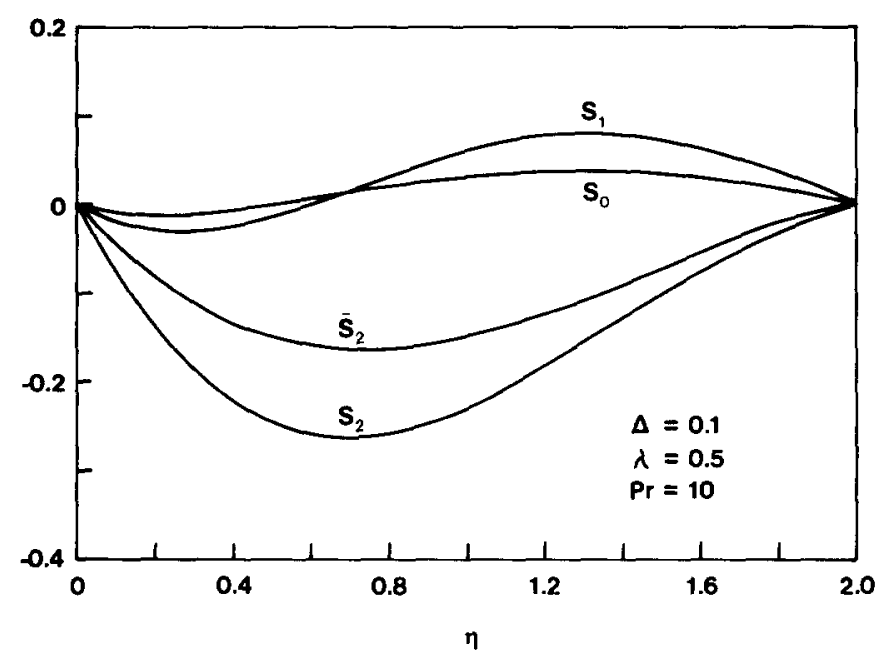

Fig. 5. Distribution of angular velocity functions (far away from the leading edge).

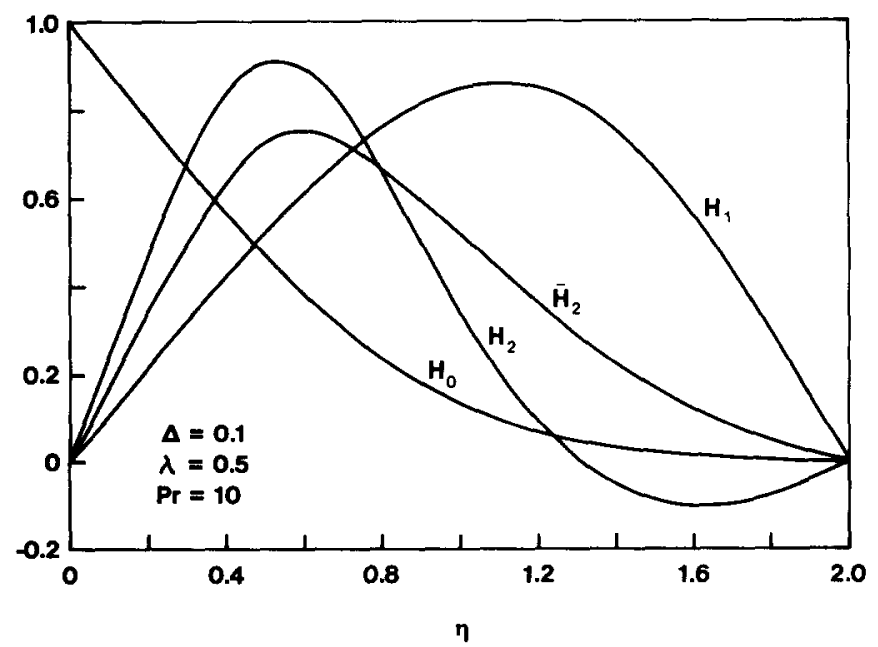

Fig. 6. Distribution of temperature functions (far away from the leading edge). 
Table 4. Values of $F_{0}^{\prime \prime}(0), F_{1}^{\prime \prime}(0), F_{2}^{\prime \prime}(0)$ and $\tilde{F}_{2}^{\prime \prime}(0)$ (far away from the leading edge solution)

\begin{tabular}{cccccc}
\hline$\Delta$ & $\lambda$ & $F_{0}^{\prime \prime}(0)$ & $F_{1}^{\prime \prime}(0)$ & $F_{2}^{\prime \prime}(0)$ & $\bar{F}_{2}^{\prime \prime}(0)$ \\
\hline 0.00 & 0.5 & 0.4151000 & 0.2460000 & 0.2467601 & $-4.219 \mathrm{E}-04$ \\
0.00 & 5.0 & 0.4150000 & 0.2460005 & 0.2467601 & $-4.219 \mathrm{E}-04$ \\
0.10 & 0.5 & 0.3784970 & 0.6840744 & 0.4407601 & $-3.619 \mathrm{E}-04$ \\
0.10 & 5.0 & 0.3784970 & 0.6840745 & 0.4406601 & $-3.619 \mathrm{E}-04$ \\
0.15 & 0.5 & 0.3745670 & 0.2510004 & 0.2086601 & $-3.869 \mathrm{E}-04$ \\
0.15 & 5.0 & 0.3745670 & 0.2514004 & 0.2086601 & $-3.869 \mathrm{E}-04$ \\
\hline
\end{tabular}

Table 5. Values of $S_{0}^{\prime}(0), S_{1}^{\prime}(0), S_{2}^{\prime}(0)$ and $\bar{S}_{2}^{\prime}(0)$ (far away from the leading edge solution)

\begin{tabular}{cccccc}
\hline$\Delta$ & $\lambda$ & $S_{0}^{\prime}(0)$ & $S_{1}^{\prime}(0)$ & $S_{2}^{\prime}(0)$ & $S_{2}^{\prime}(0)$ \\
\hline 0.00 & 0.5 & $-4.154 \mathrm{E}-10$ & $-3.377 \mathrm{E}-06$ & $-3.424 \mathrm{E}-06$ & $-2.243 \mathrm{E}-08$ \\
0.00 & 5.0 & $-4.154 \mathrm{E}-10$ & $-3.377 \mathrm{E}-06$ & $-3.424 \mathrm{E}-06$ & $-2.243 \mathrm{E}-08$ \\
0.10 & 0.5 & $-1.250 \mathrm{E}-03$ & $-8.158 \mathrm{E}-03$ & $-2.262 \mathrm{E}-03$ & $2.500 \mathrm{E}-06$ \\
0.10 & 5.0 & $-1.245 \mathrm{E}-04$ & $-8.551 \mathrm{E}-04$ & $-2.235 \mathrm{E}-04$ & $2.877 \mathrm{E}-04$ \\
0.15 & 0.5 & $-1.935 \mathrm{E}-04$ & $-8.008 \mathrm{E}-03$ & $-2.406 \mathrm{E}-03$ & $4.165 \mathrm{E}-06$ \\
0.15 & 5.0 & $-1.877 \mathrm{E}-04$ & $-8.719 \mathrm{E}-04$ & $-2.375 \mathrm{E}-04$ & $4.325 \mathrm{E}-07$ \\
\hline
\end{tabular}

Table 6. Values of $H_{0}^{\prime}(0), H_{1}^{\prime}(0), H_{2}^{\prime}(0)$ and $\bar{H}_{2}^{\prime}(0)$ (far away from the leading edge solution)

\begin{tabular}{cccccc}
\hline$\Delta$ & $\lambda$ & $H_{0}^{\prime}(0)$ & $H_{1}^{\prime}(0)$ & $H_{2}^{\prime}(0)$ & $\bar{H}_{2}^{\prime}(0)$ \\
\hline 0.00 & 0.5 & -1.1466373 & $-7.917 \mathrm{E}-02$ & 0.6894727 & $-1.352 \mathrm{E}-03$ \\
0.00 & 5.0 & -1.1466373 & $-7.917 \mathrm{E}-02$ & 0.6894727 & $-1.352 \mathrm{E}-03$ \\
0.10 & 0.5 & -1.1046667 & 1.073500 & 2.1962214 & $-1.352 \mathrm{E}-03$ \\
0.10 & 5.0 & -1.1046667 & 1.0735000 & 2.4191546 & $-1.352 \mathrm{E}-03$ \\
0.15 & 0.5 & -1.1112000 & $-4.70000 \mathrm{E}-02$ & 0.2086601 & $-1.352 \mathrm{E}-03$ \\
0.15 & 5.0 & -1.1112000 & $-4.70000 \mathrm{E}-02$ & 0.6553018 & $-1.352 \mathrm{E}-03$ \\
\hline
\end{tabular}

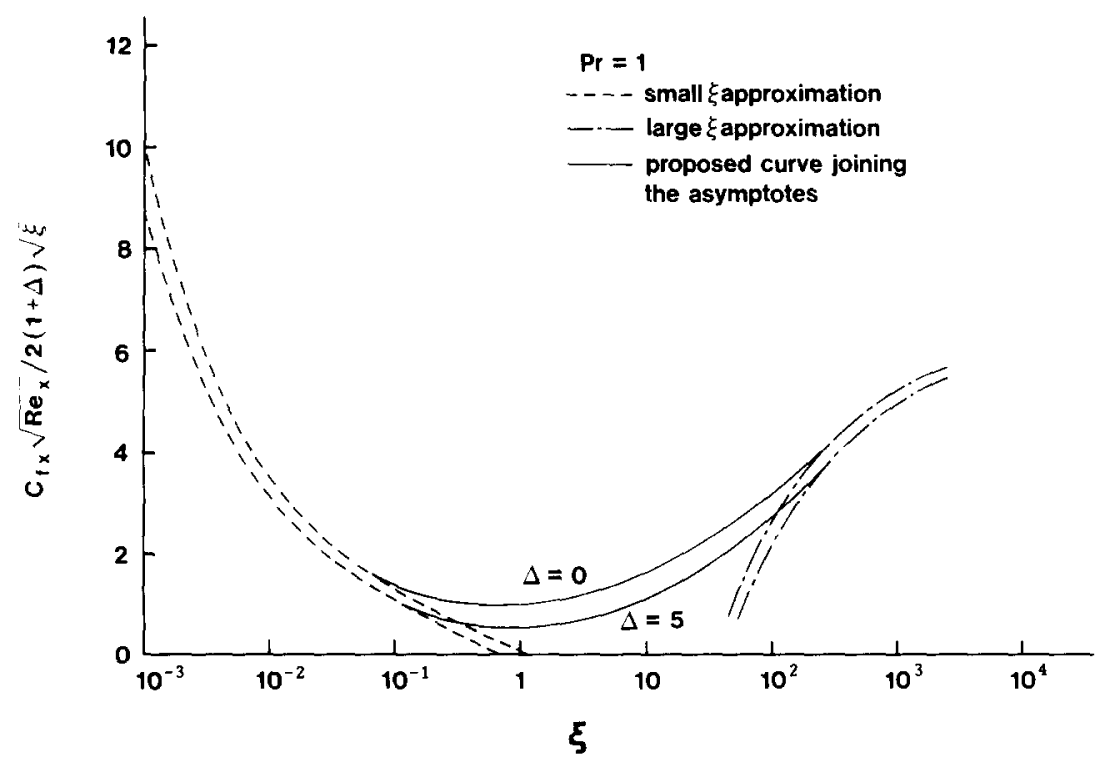

Fig. 7. Friction factor vs $\xi$.

\section{CONCLUDING REMARKS}

The theory of micropolar fluids due to Eringen is used to formulate a set of boundary layer equations for the mixed convective flow of an incompressible micropolar fluid along a vertical plate. Asymptotic solutions are presented for two regions, namely, the region close to the leading edge and the region far away from the leading edge. Numerical results are presented to illustrate the flow and heat transfer characteristics and their dependence on the material properties. The missing values of the velocity, angular velocity and thermal functions are tabulated for a range of values of the dimensionless material properties and Prandtl number of the fluid. 


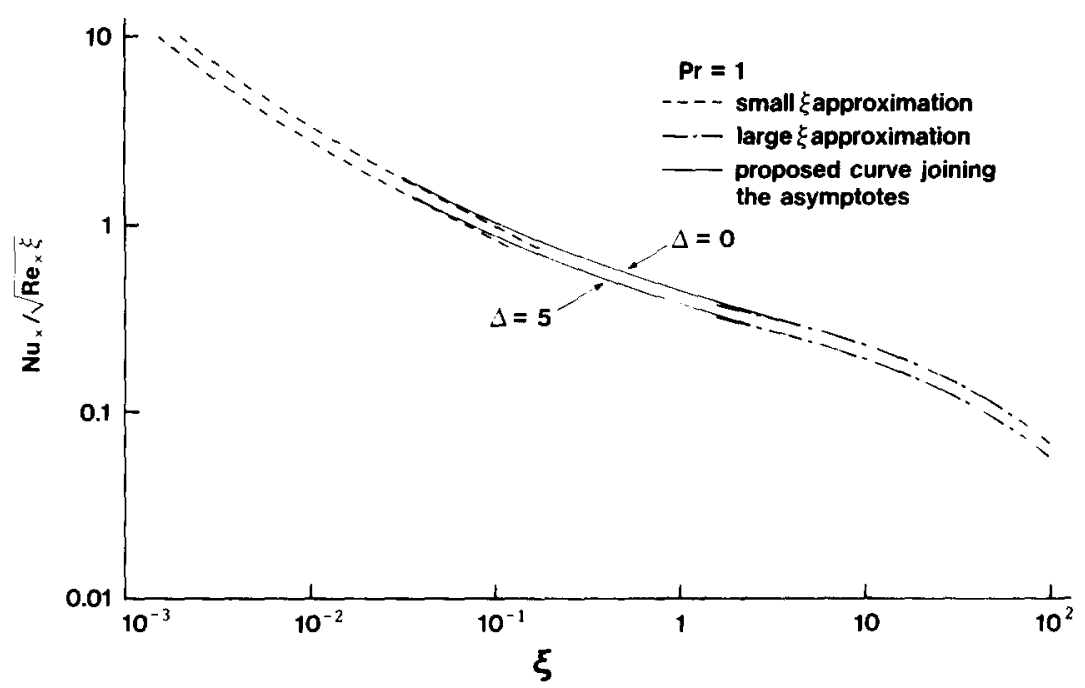

Fig. 8. Heat transfer rate vs $\xi$.

Acknowledgements-The authors are grateful to the reviewers for their constructive comments which have helped in the improvement of the quality of the paper. Thanks are due to Professor A. C. Eringen for his helpful advice.

\section{REFERENCES}

[1] E. M. SPARROW and J. L. GREG, J. Appl. Mech. 81, 133 (1959).

[2] A. A. SZEWCZYK, J. Heat Transfer 86, 501 (1964).

[3] J. H. MERKIN, J. Fluid Mech. 35, 439 (1969).

[4] A. C. ERINGEN, J. Math. Mech. 16, 1 (1966).

[5] A. C. ERINGEN, J. Math. Anal. Appl. 38, 480 (1972).

[6] R. S. R. GORLA, Int. J. Engng Sci. 18, 611 (1980).

[7] R. S. GORLA, Int. J. Engng Sci. 21, 791 (1983).

[8] S. K. JENA and M. M. MATHUR, Int. J. Engng Sci. 19, 1431 (1981).

(Received 30 October 1989)

\section{NOMENCLATURE}

$\begin{array}{ll}f, F & \text { dimensionless velocity } \\ g, S & \text { dimensionless microrotation } \\ \mathbf{G r} & \text { Grashoff number } \\ h & \text { heat transfer coefficient } \\ j & \text { microinertia per unit mass } \\ L & \text { characteristic length } \\ N & \text { angular velocity } \\ \mathrm{Nu} & \text { Nusselt number } \\ p & \text { pressure } \\ \mathrm{Pr} & \text { Prandtl number } \\ q & \text { surface heat flux } \\ \mathrm{Re} & \text { Reynolds number } \\ T & \text { temperature } \\ u & \text { velocity in } x \text {-direction } \\ v & \text { velocity in } y \text {-direction }\end{array}$

$\begin{array}{ll}U_{\infty} & \text { velocity at the boundary layer edge } \\ \boldsymbol{x} & \text { distance along the surface } \\ y & \text { distance normal to the surface } \\ \psi & \text { stream function } \\ \mu & \text { viscosity coefficient } \\ \rho & \text { density of the fluid } \\ \xi & \text { buoyancy parameter } \\ \theta, H & \text { dimensionless temperature } \\ \Delta, \lambda, G & \text { dimensionless material properties }\end{array}$

Subscripts

w surface conditions

$\infty \quad$ conditions far away from the surface 